\title{
Repertórios do conhecimento em disputa: trabalhadores indígenas e agricultores no colonialismo português em Angola, 1950
}

Contentious repertoires: indigenous workers and peasants in the Portuguese colonialism in Angola, 1950

\section{Carla Susana Alem Abrantes}

\section{(2) OpenEdition Journals}

\section{Edição electrónica}

URL: http://journals.openedition.org/aa/678

DOI: $10.4000 / a a .678$

ISSN: 2357-738X

\section{Editora}

Programa de Pós-Graduação em Antropologia Social (UnB)

\section{Edição impressa}

Data de publição: 1 junho 2014

Paginação: 195-218

ISSN: 0102-4302

\section{Refêrencia eletrónica}

Carla Susana Alem Abrantes, «Repertórios do conhecimento em disputa: trabalhadores indígenas e agricultores no colonialismo português em Angola, 1950», Anuário Antropológico [Online], v.39 n.1 | 2014, posto online no dia 01 outubro 2014, consultado o 28 abril 2021. URL: http:// journals.openedition.org/aa/678; DOI: https://doi.org/10.4000/aa.678

Este documento foi criado de forma automática no dia 28 abril 2021.

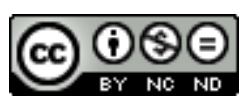

Anuário Antropológico is licensed under a Creative Commons Atribuição-Uso Não-Comercial-Proibição de realização de Obras Derivadas 4.0 International. 


\section{Repertórios do conhecimento em disputa: trabalhadores indígenas e agricultores no colonialismo português em Angola, 1950}

Contentious repertoires: indigenous workers and peasants in the Portuguese

colonialism in Angola, 1950

Carla Susana Alem Abrantes

\section{NOTA DO EDITOR}

Recebido em: 13/01/2014

Aceito em: 13/03/2014

\section{Introdução}

1 Uma análise das narrativas produzidas durante o colonialismo português do século XX encontraria facilmente representações estereotipadas de populações angolanas em contraponto com as de superioridade racial dos portugueses - ambas as imagens devedoras de uma longa história de expansão e contato. ${ }^{1}$ Os heróis europeus da descoberta e da civilização e os homens africanos, indígenas, mantidos em posição de subjugação e inferioridade e, assim, destinados ao trabalho compulsório, compunham a geografia imperial presente no imaginário de qualquer cidadão português nascido no governo de Antonio Salazar, o Estado Novo. Foi em 1930, com o Ato Colonial, que se lançaram as bases jurídicas imperiais sobre as quais se solidificou a visão de uma missão histórica do povo português para possuir e colonizar domínios distantes e civilizar suas populações. ${ }^{2}$ 
O colonialismo é compreendido como um sistema de governo construído pela violência, pela imposição de valores ocidentais e pela subjugação de populações autóctones que habitaram territórios ocupados pela expansão europeia (Cooper, 2005; Comaroff, 1989), bem como espaço social em que se criaram estruturas de governo da diferença (Mandani, 2012, 1996). O sistema colonial português - que passou a ser analisado antes mesmo de ter deixado de existir (Duffy, 1959; Anderson, 1964; Chilcote, 1967) - é conhecido como um dos colonialismos mais longos da história. Resultou de um governo que não mediu esforços para manter o controle dos seus territórios ultramarinos (em África e Ásia) após 1960, quando outras ex-metrópoles aceitaram as independências e construíram novas modalidades de cooperação governamental internacional (Pélissier, 1979; Ferreira, 1977; Bender, 1980). Nos anos que se seguiram à II Guerra Mundial, a justificativa para a presença portuguesa em África ganhou novos contornos com a participação de Gilberto Freyre, sociólogo brasileiro, na produção de teorias sobre a presença portuguesa nos espaços do ultramar (Freyre, 1951, 1952). O luso-tropicalismo, como ficou conhecida a sua teoria, propunha um "modo português de estar no mundo" pautado pela ideia de um relacionamento harmonioso do povo português com outros povos, culturas e territórios a partir de sua identidade "plástica", "tolerante" e "fraterna" (Castelo, 1998). Por meio dessas ideias, os intelectuais portugueses passaram a buscar novas identidades de contato (de si e do outro) e a caracterizar a ação colonial portuguesa como igualitária e adaptável aos modos de vida dos africanos, sem, no entanto, colocar em questão o nacionalismo protuberante e a estrutura hierárquica que se cristalizara nas relações com os territórios dominados.

3 Por sua história particular, a experiência portuguesa tem interessado aos estudiosos que se dedicam a compreender os processos de dominação, em especial no que se refere aos interstícios entre conhecimento, cultura e poder. Para além de se constatar um padrão nas narrativas coloniais - como o racismo dos anos 1930 ou o luso-tropicalismo dos anos 1950 - importa tecer uma discussão mais aprofundada sobre os modos de produção de conhecimento. Diversos estudos sobre o colonialismo português vêm marcando algumas fronteiras nesse sentido, ao colocar no centro de sua análise os processos políticos que tiveram lugar no contexto colonial (Alexandre, 2000; Thomaz, 2007), em especial a conexão dos espaços de produção de conhecimento e suas interfaces com o Estado (Pereira, 1987, Gallo, 1988; Paulo, 1992, 2001; Carvalho, 2004). Ao se conhecerem as estratégias utilizadas pelas potências coloniais para expandirem os seus domínios e, em particular, as suas formas de conhecimento, identificação, registro e disciplina, é possível compreendê-las a partir das tensões e das negociações que ocorreram entre os Estados europeus e, assim, complexificar a experiência colonial (Dirks, 1992; Cohn, 1996; Stoler, 2009).

4 Tendo como objetivo aprofundar o conhecimento sobre as agências do colonialismo português (Thomas, 1994), este artigo coloca em evidência os participantes de um cenário particular: os alunos inscritos no curso de Administração Colonial em Lisboa, nos anos 1950. A partir deste microuniverso, analisam-se as dissertações de licenciatura produzidas sobre Angola. ${ }^{3}$ Examinar os "repertórios em disputa" (Tilly, 2000) nos conduzirá pelas estradas do conhecimento produzido no contexto colonial, abrindo espaço para destituir essas narrativas de sua onipresença ao colocá-las como parte de um jogo político criado no encontro colonial (Asad, 1973). Analisar-se-á um gênero muito específico do discurso colonial: o de uma ciência construída a partir do 
ensino superior metropolitano responsável pela transmissão de conhecimentos para gerações mais novas, futuros agentes da administração dos territórios no ultramar.

5 As fontes aqui analisadas foram localizadas durante pesquisa realizada em Lisboa, entre 2007 e 2010, em arquivos, bibliotecas, e entrevistas com os participantes daquele contexto de ensino nos anos 1960 - motivadas pelo interesse inicial em traçar uma genealogia do africanismo em Portugal (Maino, 2005) e, assim, percorrer as bases sobre as quais se assentaram saberes para a manutenção de desigualdades (Souza Lima, 2007). As dissertações foram apropriadas como práticas que ganharam existência a partir das condições de um determinado campo social e do comprometimento de seus agentes (Bourdieu, 1968), fazendo parte de um vasto conjunto de acontecimentos dispersos que poderiam ser identificados através da descrição (Foucault, 1971). Procurou-se identificar o contexto em que determinadas ideias foram manifestadas, que elementos esconderam e quais revelaram, que continuidades irrefletidas foram guardadas e como foram organizadas no interior de uma unidade narrativa específica tomada como resultado final de um processo de ensino: as dissertações de licenciatura.

De um total de 80 dissertações de licenciatura escritas sobre Angola, seis foram selecionadas para uma análise mais aprofundada e minuciosa voltada à compreensão das condições sociais que viabilizaram as representações sobre as populações angolanas. Considerei-as, assim, como produtos de "zonas de contato", campos de possibilidades que tiveram sua própria história e que se constituíram em dependência dos objetos da ação, por meio dos quais se imaginaram populações e modos de intervir sobre elas. As ações coloniais passam então a ser percebidas a partir de textos, objetos de pesquisa, teorias mediadoras, problemas e soluções formulados sobre e para um Estado colonial em expansão em Angola, nos anos que se seguiram à II Guerra Mundial. Dentre os repertórios do conhecimento em disputa, a educação se mantém como um projeto consensual e um dos métodos mais eficazes - e legítimos naquele contexto para dar continuidade aos projetos coloniais.

\section{As dissertações de licenciatura, seus objetos e autores}

7 Como produtos das dinâmicas institucionais do ensino superior, as dissertações de licenciatura constituíam uma escrita muito particular, e um momento/ritual obrigatório para a finalização do curso complementar de dois anos em Administração Colonial oferecido pelo Instituto Superior de Estudos Ultramarinos (ISEU), em Lisboa. ${ }^{4}$ Com essa titulação, o licenciado seria um "especialista" em "problemas coloniais", apto a ocupar posições da alta hierarquia da administração nas colônias e a garantir à sua instituição de origem uma maior responsabilidade e posição política nos assuntos da gestão colonial. A dissertação, como um gênero, está assim pautada por uma linguagem dinâmica e possível dentro de uma relação mais ampla que se estabeleceu entre esta instituição de ensino e pesquisa e as outras instâncias administrativas, tanto na metrópole como nas colônias, conformando uma rede ampla da administração em que tais saberes ganharam significado, aspecto que ultrapassa os objetivos do presente artigo.

Uma das temáticas privilegiadas nesses estudos especializados era o trabalho em Angola. Nos anos 1950, a ideia predominante era de que as populações africanas, indígenas, eram 
destinadas ao trabalho. Esta concepção era compartilhada pelos portugueses, de um modo geral. A dissertação de um dos alunos, Afonso Mendes, (1958) trata deste tema. Como o título, "A Huíla e Moçamedes: considerações sobre o trabalho indígena", Mendes trata do problema do recrutamento de trabalhadores para uma economia em expansão que procurava negociar com as agências internacionais, as quais passaram a estabelecer limites para a ação colonial europeia naqueles anos.

9 A sua narrativa dá sinais de uma transição do sistema regido pelo Estatuto do Indigenato para um novo modelo de submissão dos africanos, na medida em que os braços continuavam a ser necessários. ${ }^{5}$ Essa transição está expressa na maneira como Mendes comunica a questão que procura desenvolver em sua dissertação. Por um lado, o indígena é caracterizado como condicionado por uma lógica de "usos e costumes que levaram séculos a criar-se", de uma "preguiçosa existência que aprendera[m] de seus antepassados, de modo algum desejando relações com o trabalho regular e constante" (Mendes, 1958, p. 86) e "entregues a si mesmos e sem força de vontade" para um esforço voltado para o maior rendimento no trabalho (Mendes, 1958, p. 129). Por outro, o indígena torna-se objeto de conhecimento para que se compreendam as suas "vontades" e se garantam soluções para que a força de trabalho seja mantida.

Estas marcas no texto de Mendes reafirmam os termos e as ideias que passaram a vigorar em 1928, segundo as quais o africano era visto pela sua obrigatoriedade em relação ao trabalho. Mas o autor também se apropria dos novos termos trazidos pelas políticas igualitárias e de não discriminação racial, incentivadas sobretudo pela Organização Internacional do Trabalho (OIT). Um novo léxico governamental se formava e Mendes, muito embora tenha incorporado em seu texto alguns elementos desse novo padrão, manteve uma adesão à antiga linguagem. Outros colegas de curso davam passos mais arriscados em direção a uma escrita marcada pela inovação.

11 Amadeu Castilho Soares foi um deles. Também aluno do ISEU e formado no ano seguinte ao de Afonso Mendes, Castilho Soares foi participante ativo, nesses anos de virada, no modo de perceber o colonialismo português, lidando com a questão das populações africanas a partir de uma ideia de integração social. Em paralelo ao problema dos trabalhadores quanto a uma economia cafeeira e algodoeira que fora elaborada por Afonso Mendes, Castilho Soares aborda a questão dos agricultores que, na sua perspectiva, seriam trabalhadores rurais e ainda indígenas. Somos remetidos, através de seu texto, a diferentes povos do território angolano, objetos de seu estudo sobre o "bem-estar rural".

12 O autor nos leva à região central de Angola, o Cuanza Sul, onde lhe é apresentado um "denso aglomerado humano" fixo às margens do rio Cuvo, cuja beleza natural não compensa a "imprevidência dos seus habitantes e o primitivismo das suas técnicas de exploração do solo, pelo que há ali fome, por vezes” (Soares, 1961:28); ao Munhino, região da Huíla ao sul da colônia, onde estavam "pequenos agricultores" fixados há muitos anos e "com razoável nível de evolução", que se dedicavam às culturas de feijão, milho e café e tinham a posse de algumas cabeças de gado bovino e porcino; a Caconda, norte da colônia, em que havia regiões agrícolas com "populações estabilizadas em aldeamentos naturais extensos, grande número com mais de 100 fogos, havendo sobados com mais de 1000 famílias no aglomerado" (Soares, 1961:38). Nesta última região, o autor escreve que o agricultor - definido como do povo Quioco - considerava a sua profissão "dignificante" para o próprio grupo. ${ }^{6}$ 

Os agricultores de Castilho Soares continuam sendo representados por características antigas, ligadas a uma raça africana, muito embora com uma roupagem nova que supostamente os dignificaria e os manteria como objetos não apenas do conhecimento, mas de políticas de controle destinadas à organização de uma economia colonial, agrícola. Assim, sendo objetos construídos para um plano de desenvolvimento, os indígenas agricultores de Soares se distinguiam dos indígenas trabalhadores de Mendes, preparados para políticas de trabalho, muito embora ambas as formulações mantivessem pontos em comum ao colocarem os africanos em posições de fragilidade e de carência e, portanto, sob a vigilância dos agentes da administração colonial portuguesa.

podrão pode encontrado nas demais dissertaçôes de licenciatura em que outros objetos de estudo ganharam existência: os trabalhadores autônomos e os proprietários de terra de José Monteiro (1959), que se preocupava com uma "economia nativa" a ser valorizada. E as comunidades rurais de José Pereira Neto (1960), que pensava em novos alvos de intervenção, desenvolvimento e cooperação em meio à sua tentativa de diálogo com as agências internacionais (tais como a ONU e a UNESCO). Assim, nos anos 1950, os sujeitos/objetos considerados "problemas" para a administração foram ampliados a partir da escrita dos futuros licenciados pelo ISEU e fizeram emergir duas correntes em disputa no interior da instituição: uma que apreendia a realidade social angolana como constituída por trabalhadores e outra que a percebia a partir das lentes das ciências sociais, como composta por agricultores e comunidades rurais, como veremos adiante.

\section{Teorias negociadas e em exibição}

Em comum, ambas as correntes tomaram as populações angolanas como objetos de reforma social, ou digamos, de assimilação, tendo em vista procedimentos variados de escrita e em negociação com professores e outros autores do cenário nacional e internacional. Os modos de perceber os africanos eram selecionados a partir de um leque abrangente de características reelaboradas de antigos textos coloniais e também de novos autores. Como sugere Charles Tilly (1997), as performances individuais ocorrem diante de guias condutores (scripts) e do conhecimento local compartilhado, e dependem de um conjunto complexo de processos que estabelecem os limites para as histórias que delas resultam. Castilho Soares, Mendes e os demais alunos-autores representaram populações africanas por meio de recursos narrativos que ganharam existência e significado no interior de uma configuração de indivíduos, estes com trajetórias muito particulares.

Castilho Soares aproxima-se da realidade angolana integrando uma das missões de pesquisa promovida pelo Centro de Estudos Políticos e Sociais em colaboração com a Junta de Investigações Ultramarinas. ${ }^{7}$ A sua dissertação, intitulada "Política de BemEstar Rural em Angola (Ensaio)", pode ser enquadrada como um trabalho de antropologia aplicada comprometida com o regime colonial. Nela, o aluno-autor afirma:

Torna-se, por isso, imprescindível conhecer os motivos que fazem agir essa sociedade ou sociedades, isto é, as suas motivações. Todas essas motivações nos poderão parecer bizarras e sem valor, mas o que mais importa não é saber, precisamente, o que nós pensamos. O que importa é saber o que os próprios indígenas pensam, porque, se desprezarmos as coisas que têm para eles um interesse supremo, a legislação, repousando sobre o mau entendimento inicial, 
arrisca-se a causar mais mal que bem e a destruir irremediavelmente o que não poderemos, talvez, jamais, substituir (Soares, 1961:191, grifos do autor).

$\mathrm{Na}$ citação acima encontra-se o único termo em negrito das quase 300 páginas da dissertação. A ênfase em "motivos" (dos africanos) é reveladora da orientação teórica de uma antropologia culturalista que resultou do diálogo que o autor estabeleceu com Jorge Dias, professor do ISEU. Recém-ingressado no quadro de professores daquela instituição, Jorge Dias propunha um desenvolvimento culturalista com tendência à valorização das pessoas, de seus sentimentos e pensamentos. Naqueles anos, os antropólogos em Portugal haviam deixado de lado as marcas da tradição e do pitoresco para dar lugar a novos modos de percepção centrados em pessoas, grupos, processos culturais e sociais (Leal, 2006:173). Tais formulações - em sintonia com os trabalhos da antropologia cultural americana, tais como os de Ruth Benedict - influenciaram o trabalho do professor Jorge Dias, que marcaria uma oposição ao seu colega, também professor da casa, Mendes Correia, especializado nas ideias da antropologia biológica.

Essa teria sido a investigação antropológica possível naquele contexto. Segundo Rui Pereira (1987), ao se conhecerem as motivações e as aspirações dos africanos, criava-se uma nova "operação cosmética" no discurso colonial, que mantinha, em silêncio, a antropologia como um dos instrumentos de reforço tanto da ocupação portuguesa nos territórios como de ampliação do trabalho forçado dos africanos. Assim, em conexão com as demandas coloniais, a nova linguagem utilizada por Castilho Soares, ao representar os agricultores de Angola, exibia autores que marcaram a sociologia e a antropologia naquele momento de renovação dos conteúdos e de institucionalização das ciências sociais em Portugal (Pereira, 1987; Leal, 2006:167-181; Castelo, 2012). O meio rural emergia como um dos objetos privilegiados na produção intelectual de outros antropólogos, assim como crescia o interesse pelas sociedades camponesas em diferentes partes do mundo, em especial na antropologia americana e inglesa.

As teorias de autores coloniais e pós-coloniais foram ressignificadas naquela configuração acadêmica muito particular. Foi assim que as propostas de uma sociologia rural produzida no México estiveram incorporadas ao texto ao se considerar a produção agrícola como a base para o sustento da humanidade, da economia e da política dos modernos Estados-nação (Soares, 1961:92). Também foi pela via de intelectuais mexicanos que Castilho Soares apresentou as populações étnica e culturamente heterogêneas de Angola como um dos "traços característicos das relações sociais nos meios rurais". A sociologia mexicana forneceria um enquadramento teórico e metodológico para auxiliar os gestores portugueses na criação de uma "base científica na política que se dirigia a solucionar esses problemas e a procurar a elevação moral e material das condições de vida de gentes do campo" (Soares, 1961:230). ${ }^{8}$ Autores franceses como Georges Balandier e Roger Bastide estavam incluídos nesse repertório para justificar o levantamento de dados e os propósitos de um novo ideal de coletividade, luso-tropical. Assim, com propostas de "igualdade", "pluralidade" e "modernidade", Castilho Soares e outros alunos mantiveram a expectativa de ver os africanos transformados em futuros portugueses, com narrativas orientadas a partir das ciências sociais.

Tais narrativas luso-tropicalistas e marcadamente sociológicas se opunham a outras dissertações que lidaram com os trabalhadores indígenas, cujos conteúdos eram enquadrados pelas teorias do direito, com propostas de examinar práticas normalizadas no cotidiano da administração colonial e procedimentos normativos que viabilizassem 
a restrição gradual do uso de trabalho escravo e compulsório - em diálogo com a OIT, como já mencionado. ${ }^{9}$ A questão central discutida por este grupo de alunos estava centrada na busca por soluções "modernas" e mais "compreensivas" que substituíssem as práticas repressivas e impositivas em uso no passado, como encontramos explicitamente marcado nas dissertações de dois alunos, Américo Castanheira (1950) e João Herculano Moura (1955). “Abusos”, “maus-tratos", "práticas abusivas” são termos abundantes nos textos sob esta orientação, buscando explicar o que não mais seria permitido no comportamento dos funcionários coloniais. Essas narrativas mostram que, para que a ação colonial fosse viável nos anos 1950, haveria a necessidade de um Estado "limpo" das marcas de abusos e de discriminação. Ideias de "igualdade", "harmonia", "políticas não discriminatórias" e com ênfase no "social" eram usadas para contrapor as referências à "escravidão", aos "horrores", às "desumanidades", trazendo para a questão do trabalho indígena novas possibilidades discursivas.

21 Antepassados portugueses foram recuperados nesses textos. Suas vozes anunciavam um dos principais objetivos das "ciências da colonização": "determinar positivamente a intervenção que o Estado deve ter na colonização e a orientação que nela o deve guiar" (Moura, 1955:III). Estes ideais de um Estado português reproduzidos pelos alunosautores dos anos 1950 remetem o leitor a ideias do início do século XX, de autores como Ruy Ulrich, José Gonçalo Santa Rita, Lopo Vaz de Sampaio e Melo e outros que forjaram as marcas da ação colonial portuguesa. ${ }^{10}$ Logo, encontra-se nas dissertações de licenciatura desse segundo grupo uma reelaboração das antigas formulações racializadas criadas no início do século XX mescladas às propostas de direitos iguais e plurais e de assimilação sem, no entanto, perderem a aparência de um modo de narrar "tradicional". Talvez por isso, na guerra de foices travada no apagar das luzes do regime jurídico criado com o Estado Novo, com a abolição do Estatuto do Indigenato em 1961, tal corrente tenha perdido espaço no interior do ISEU.

\section{Resistências solapadas pela escrita}

Como já destacado, os novos modelos de integração gestados nesse período tardio do colonialismo português, apesar de suas ênfases igualitárias, deram continuidade à identificação das populações africanas como objeto de reparação, correção e transformação. As expectativas de similitude e o não reconhecimento da diferença estariam na base da expansão colonial portuguesa, como sugeriu Cristiana Bastos (1998). Com um "nós" pronunciado que silenciava o "outro", o colonialismo português solapou as resistências pela escrita.

Diante dos ideais de similitude que restringiam o pensamento dos pesquisadoresalunos, as propostas de administração mantiveram-se como estruturas fiéis aos textos. Ambas as frentes de reflexão intelectual, ao procurarem redimir a colonização dos maus hábitos e dos comportamentos abusivos, valorizavam as soluções da administração e as práticas de ajuda e promoção da ordem. Encontram-se na dissertação de Castilho Soares experiências de administração descritas com primor, inscritas nos projetos nacionais de fomento lançados naquela década e considerados pelo autor como "vigorosos impulsos" de "evolução econômica e cultural das populações rurais" (Soares, 1961:47). ${ }^{11}$ Tais ações da administração em território angolano colocariam "ordem e organização" na agricultura dos nativos, esta considerada "presentemente inorgânica e desarticulada" (Soares, 1961:48), e 
introduziria sistemas e práticas modernos que permitissem a fixação do nativo a terra como um verdadeiro agricultor. As atividades de agricultura das sociedades africanas nessas regiões passariam a ser reguladas pelo Estado, suas terras divididas e suas sementes selecionadas conforme o entendimento de uma "boa agricultura".

As dissertações de licenciatura muitas vezes se assemelhavam a manuais voltados para um público da nova geração de administradores coloniais: propunham regras a serem conhecidas e seguidas pelos colegas mais jovens que trabalhariam diretamente com as populações, impondo diretrizes e equacionando dificuldades. Essa orientação dos textos transformaria os alunos, autores das dissertações, nos verdadeiros intérpretes da realidade ultramarina, conhecedores de um novo modo de agir colonial mais "humanitário" e com "disposições idôneas" que não comprometessem "a obra em marcha" (Monteiro, 1959). As pretensões à similitude ganhavam assim, pela via da comunicação escrita, um reforço burocratizado que dispunha e impunha um padrão de conhecimento sobre a realidade colonial envolto em imagens de sucessos da empreitada no ultramar. Talvez fosse este um modo de fazer frente à fragilidade e à decadência do colonialismo português, alimentadas desde o século XIX como um recurso eficaz na produção de modelos de ação - como sugeriu Wilson Trajano Filho (2003) em sua reflexão sobre a "pedagogia dos fracos".

25 Mas em raros momentos a propaganda das ações do Estado é suspensa. Em Castilho Soares, encontra-se uma pequena nota, à página 58 , que revela, para surpresa do leitor, que a agricultura nativa talvez pudesse estar organizada em outros termos e sem grandes necessidades de especialistas estrangeiros: "O nativo colhe a mandioca consoante às suas necessidades alimentares e monetárias, entre os dezoito meses e os três anos após a plantação. A terra funciona como silo" (Soares, 1961:58). A breve menção a uma vida organizada e autossuficiente não produz grandes efeitos sobre o restante da narrativa, e a sua existência em uma nota de página talvez tenha sido permitida pelo autor em um momento de pausa dos impulsos de uma cultura europeia em busca do seu ideal (Stoler, 2009). As condições e o breve tempo da pesquisa realizada por Castilho Soares em Angola podem ter contribuído para uma reduzida observação dos modos de agricultura local.

26 Castilho Soares era português, tendo tido uma vivência em África muito breve - apesar de tê-la sonhado e imaginado nos seus tempos de escola e através da memória de parentes que emigraram para Angola (Soares, 2011). ${ }^{12}$ Os demais alunos do ISEU tiveram experiências diversas antes de se matricularem no curso de Administração. Ao contrário de Castilho Soares, muitos tiveram vivências mais abrangentes em África, em especial como funcionários do quadro administrativo. Afonso Mendes, Américo Castanheira e José Monteiro escreveram suas dissertações a partir dessas vivências em Angola. Mesmo assim, o guia condutor colonial se manteve em seus textos, impedindo um conhecimento mais profundo sobre as sociedades africanas.

Afonso Mendes passou seis anos em posições da administração colonial como chefe de posto na Circunscrição do Baixo Cunene, sul de Angola. Em seu esforço de narrar e descrever a realidade angolana, Mendes apresentou os princípios recebidos no ensino superior complementar do ISEU, marcados pela defesa de humanidade e igualdade nas relações de trabalho. Sua dissertação foi publicada no mesmo ano em que foi escrita, 1958, também como um dos números do periódico apoiado pelo CEPS. Seu texto foi reconhecido naquela época por elaborar de forma primorosa o problema do trabalho 
indígena. Ao mesmo tempo, nos deixou um registro da violência perpetrada pelos portugueses em Angola, como encontramos no trecho abaixo.

Dentro de suas possibilidades, as autoridades administrativas esforçam-se por levar os indígenas ao cumprimento desse dever, quer facilitando emprego aos que o procurem, quer recrutando para serviços de interesse geral os que sejam mais relutantes em trabalhar.

Regra geral, os homens de mais de 40 anos não são empregados em trabalho assalariado, na Huíla. Pode mesmo dizer-se que a grande massa dos trabalhadores tem idade compreendida entre os 18 e os 30 anos, sendo o mais numeroso o grupo limitado entre os 20 e 25 anos.

Ora, os trabalhos de interesse geral, como a construção e reparação de estradas, obras de arte, barragens, edificação de portos e vias férreas, construção de edifícios públicos etc. são habitualmente localizados fora das regiões de origem dos trabalhadores, mais violentos e menos bem pagos do que o trabalho oferecido pelas outras empresas. As autoridades procuram recrutar para esses serviços, tanto quanto possível, os indígenas mais preguiçosos, e só depois os que estejam, no momento, inativos. Quer dizer, o indígena que se encontre sem trabalho pode ser recrutado para serviços de interesse geral, com as naturais consequências: afastamento da família e dos haveres, provavelmente sem se encontrar preparado para tal; ser escolhido para uma tarefa que lhe não agrada; ser submetido a uma disciplina rigorosa e a um trabalho mais pesado do que a generalidade dos outros serviços; auferir uma remuneração inferior à que receberia noutras tarefas. Como se vê, tudo isto são razões sobejas para impelirem a procurar trabalho de moto próprio, em vez de aguardar que as autoridades lho arranjem.

Infelizmente, a maioria joga com a deficiente ocupação administrativa, escondendose em pleno mato, junto de parentes ou conhecidos, ou ainda em áreas administrativas limítrofes, o tempo em que dura o recrutamento para trabalhos públicos (Mendes, 1958:66).

Ao escrever, Afonso Mendes não colocou em causa o recrutamento. Porém, ao descrevêlo e defendê-lo, permitiu que o texto fosse atravessado por fugas e resistências dos trabalhadores às imposições da administração colonial. Sendo a captura de trabalhadores uma das antigas funções da administração portuguesa em Angola, em especial nas primeiras décadas do século XX, as exigências da legislação "moderna" quanto às práticas igualitárias e às recompensas trabalhistas que emergiam nos anos 1950 não parecem abalar a crença na obrigatoriedade do trabalho por parte do africano, que continua a ser defendida pelo aluno-autor.

No entanto, o trabalho indígena se tornou um tema cada vez mais difícil de ser sustentado no espaço do ensino superior em Lisboa. Os alunos que tiveram suas pesquisas desenvolvidas sobre o assunto foram transferidos para um novo espaço institucional criado em Luanda, Angola, sob a presidência de Afonso Mendes, em 1962: o Instituto do Trabalho, Previdência e Assistência Social. ${ }^{13}$ Este órgão do Estado colonial português passou a centralizar os procedimentos da administração relacionados ao trabalho em Angola num contexto em que o novo Código de Trabalho Rural havia sido promulgado (1962). Por meio dele, funcionários capazes, recrutados, devidamente credenciados passariam a agir no território para atuarem e servirem aos desígnios de uma política marcada pelo término de "subornos", "fraudes" e "explorações", questões consideradas parte dos problemas da administração em Angola. Com o fim do Indigenato em 1961, as ideias trabalhistas de Afonso Mendes já não estavam dirigidas diretamente aos indígenas, termo que passou a ser criticado e associado a um período anterior, "colonialista". 
30 Muito embora em oposição, ambas as propostas - de reforma trabalhista e de integração e bem-estar das populações rurais - fortaleceram a máquina da administração colonial por estarem orientadas por um único objetivo: a educação como uma solução para Angola.

\section{A educação como uma solução para Angola}

31 A mágica que transformaria indígenas em “cidadãos” estaria a caminho. Integrados, estáveis, responsáveis, os africanos passariam a compor a coletividade nacional portuguesa a partir da intervenção de políticas educacionais. A educação seria a solução. Os agricultores de Castilho Soares seriam, acima de tudo, observados como possibilidades de mão de obra integrada a um modelo econômico nacional, cientificamente embasado e constituído de acordo com teóricos e governantes superiores, vigilantes em Lisboa.

Ignorando qualquer possibilidade de compreensão da agricultura desde uma perspectiva local, Castilho Soares enfatiza as "ausências" e as "faltas" das populações do território angolano e propõe que o ensino seja um dos "vértices" centrais do seu plano de desenvolvimento e bem-estar rural. Em nome do progresso, o ensino resolveria os problemas de "bloqueios", “impedimentos”, "obstáculos” da população local. Os projetos postos em ação pelos técnicos de agricultura não seriam suficientes, o que justificaria a atuação dos especialistas da área de educação, acionados como esforços complementares para modificar formas de pensar e fazer com que os destinatários das ações "entendessem" os projetos formulados pela metrópole. As ações do Estado, pela via educativa, acomodariam as populações a uma "sociedade central" e "universal". Angola, aos olhos de Soares, seria um imenso "laboratório de aculturação" por ali residir uma "sociedade em transição" com vistas a integrar-se ao grupo dos mais evoluídos, dos colonizadores, estando o projeto de ensino assente em "bases científicas" capazes de permitir identificar as características étnicas e heterogêneas das populações e garantir seu reconhecimento internacional. Estes eram os seus termos.

Entretanto, Castilho Soares reconhecia a existência do que ele chamou de uma “educação não formal", própria das populações locais, e que poderia ser aproveitada no sentido de uma "endoculturação", para assim alcançar a desejada integração nacional. Por meio de uma "pedagogia do exemplo" (Souza Lima, 1995, 2008), colocar-se-ia em prática o uso dos métodos indígenas de educação, e crenças seriam disseminadas a partir de dispositivos que fizessem com que as populações reconhecessem a si mesmas.

Os nativos estão integrados e adaptados ao seu sistema sociocultural que já encontraram ao nascer, pelo que, perante as modificações que se pretenda introduzir-lhe, é lógico que reajam contra essa intromissão e apresentem resistência. Para suavizar a dureza da intromissão dessas técnicas estranhas, há necessidade de atuar racional e metodicamente por meio de estímulos, desenvolvendo as suas artes típicas, os seus próprios jogos e divertimentos, as suas danças, ajudando a vencer as suas próprias dificuldades e obstáculos que se deparam à evolução das comunidades, dotando-as de água potável, promovendo a abertura de caminhos vicinais, dando orientações sobre salubridade e higiene e oferecendo assistência médica, criando pequenas indústrias com base na avicultura, na piscicultura, na cerâmica etc. ou iniciando práticas de exploração de seus recursos naturais (Soares, 1961:97). 
Tais propostas mostram também a entrada do Estado no âmbito da educação das populações autóctones (indígenas), até então uma esfera de atuação exclusiva da Igreja. A intenção de Soares era substituir os métodos de ensino de responsabilidade da Igreja, destinados aos "não civilizados", por novos métodos mais "modernos". A justificativa para a ação do Estado nesse domínio estaria na sua metodologia científica, que se caracterizaria, segundo o entendimento do autor, pela ausência de violência para com as sociedades africanas, ao contrário do praticado pelas missões religiosas. Soares, em sua dissertação de licenciatura, propunha a reforma do antigo sistema de ensino, que era identificado pelo seu caráter "abusivo" ao impor normas de vida diferentes das sociedades africanas "ancestrais", criando fontes de conflitos, desajustamentos emocionais, e outros problemas que não contribuiriam para os "objetivos visados pela ação civilizadora" (Soares, 1961:121).

A educação comparece como elemento de força também nos planos de reforma de outros licenciados que se especializaram no tema do trabalho indígena. A ideia de um Estado que se preocupa com a população indígena, com a proteção dos seus usos e costumes sempre esteve no escopo das ações coloniais do século XIX (Jerónimo, 2010). Deixá-los à própria sorte continuava não sendo uma boa resposta para os que se especializavam nos problemas coloniais nos anos 1950. Américo Castanheira (1950) entendia a educação como um método utilizado principalmente para os contextos rurais. A "compulsão educativa", encontrada nesta dissertação, deveria ser promovida pelas autoridades para conquistar os trabalhadores. Ela incluía filmes para informar às massas os benefícios do trabalho; aproveitamento de indivíduos educados nas missões para que exercessem cargos administrativos e influenciassem outros em fases distintas de assimilação; escolas e postos agrícolo-pecuários destinados a ensinar tanto as práticas de agricultura como o uso falado e escrito da língua portuguesa, dentre outros. Um departamento especializado no tema, idealizado por Castanheira, teria como finalidade a melhoria das condições de vida dos trabalhadores, o aumento de sua capacidade de produção, o fomento à oferta de mão de obra e, em última análise, a transformação dos indígenas em "seres capazes de iniciativas e de responsabilidades" (Castanheira, 1950:98-99).

Em José Monteiro (1959), a educação aparece como um dos métodos para que os indígenas autônomos aceitem as propostas do projeto assimilador. A educação é percebida aqui como um caminho seguro para que ao indígena seja dada a possibilidade de compreensão de um sistema pensado como o "melhor para todos". A percepção da não adequação do indígena ao sistema levou Monteiro a refletir sobre a importância dos "colaboradores" - termo que substituiria os antigos "capatazes" - conscientes de seu lugar de promotores e mobilizadores das populações indígenas, mostrando a elas os novos caminhos da civilização.

A difusão do ensino destinado aos indígenas é assim necessária e não se fazendo, constitui um dos mais frágeis pontos para o ataque a um povo colonizador, para quem a facilitação do acesso à civilização deve constituir uma das principais preocupações (Monteiro, 1959:159-160).

O objetivo seria a criação de "verdadeiros evoluídos mentais e profissionais" por meio da difusão de estabelecimentos de ensino profissional orientado e dirigido pelo Estado. Projetava-se a criação em larga escala de escolas, com conteúdos econômicos, literários e de assistência religiosa, sempre com o cuidado para que fosse[m] "adequada[s] ao seu modo de ser e à sua elevação sem sobressalto, de modo que os juízos de valor 
tradicionais fossem abandonados pela insensível pressão dos novos conceitos absorvidos" (Monteiro, 1959:187). Pela via educativa estaria resolvida a questão de manter os africanos como trabalhadores diante de um quadro de fortes críticas às práticas abusivas utilizadas no colonialismo português.

Essa moderna política colonial formulada em Lisboa e posteriormente transferida para Luanda teve sua intensidade sentida nos anos 1960/1970 em Angola pela população local, muito embora com impactos diferenciados a depender da região. Como mostra Elisete Marques da Silva (2003) para o sul de Angola, a penetração portuguesa intensificou-se nos últimos anos do colonialismo português pela rede escolar, quando a grande maioria da população africana passou a ter uma escolaridade de pelo menos alguns anos elementares. Uma rede de escolas estatais marcou uma diferença significativa no cotidiano dessas sociedades agropastoris.

\section{Considerações finais}

39 A análise das dissertações de licenciatura nos deu acesso a modos de pensamento e a algumas das condições que viabilizaram a manutenção de estruturas de desigualdade no sistema colonial português. Trabalhadores indígenas e agricultores foram categorias utilizadas para nomear as populações do território angolano e os principais marcadores dos repertórios dos alunos do ensino superior de administração em Lisboa nos anos 1950. Construídos em disputa, tais repertórios propunham não apenas modos de representar as populações angolanas, como também concebiam imagens do que deveria ser o povo português, exibiam as teorias legitimadoras de seu discurso e apresentavam formulações para a reforma da administração colonial. Os repertórios também foram formulados a partir de um diálogo com os organismos internacionais nos anos que se seguiram à II Guerra Mundial, como a OIT, a UNESCO e a ONU - agências em oposição crítica aos modelos coloniais europeus.

Estamos diante de narrativas coloniais gravadas em texto, "agencialidades coloniais particulares", como sugeriu Nicholas Thomas (1994), que produziram representações sobre as populações angolanas. Apesar das polarizações no modo de classificar as populações, as marcas orientadoras da agência colonial foram mantidas: sociedades africanas identificadas como faltantes e sociedades portuguesas, europeias, reconhecidas como plenas de direitos e de soluções para os problemas das populações locais. Estas são marcas de uma desigualdade colonial produzida a partir de imaginários desqualificadores das populações colocadas como objeto das políticas de Estado. Os projetos de educação para os africanos se transformaram no principal instrumento colonial, ou seja, de poder, que se instalou ao longo da revisão do colonialismo português nos anos 1950 .

$41 \mathrm{Na}$ ressignificação dos termos do pensamento colonial dos anos 1950 surgiram elementos da teoria luso-tropicalista de destino do povo português para coexistir harmoniosamente com outros povos e culturas, encobrindo o projeto assimilador que a sustentava. Autores mexicanos, em especial sociólogos, e suas propostas de integração das populações rurais e seus modos de vida social também são recolhidos e reformulados ao lado de teóricos da luta anticolonial e dos antigos formuladores da política portuguesa do início do século, contribuindo para uma miscelânea de ideias agregadas em uma tessitura discursiva que transmitia às novas gerações de 
administradores um ideal de colonização pautado por "boas" e "modernas" práticas governamentais de uma coletividade "nacional".

Dentre os enunciados analisados, encontram-se também elementos que escapam ao controle racional dos que passariam a ser os intérpretes da realidade angolana após a diplomação em administração. Da escrita desses alunos escapam descrições que mostram a resistência das populações à ação colonial: fugas e comportamentos contrários às expectativas da administração. Trata-se de breves momentos em que as verdades e os ideais são suspensos, muito embora seja impossível para os alunosautores constatarem tal presença em face do guião colonial que moldava e orientava a sua escrita. Tais aberturas no modo de conhecer podem ter sido produtos da experiência de pesquisa e de contato com Angola que cada um dos alunos-autores teve possibilidade de vivenciar em seu processo de formação especializada e/ou nas atividades desempenhadas em terreno africano, quando exerceram funções da administração.

A partir dos alunos-autores tomados como objetos neste artigo, apresenta-se o esforço coletivo de mudança da forma colonial portuguesa nos anos pós-II Guerra Mundial. Nos seus textos de conclusão do curso superior em administração colonial é possível identificar os complexos mecanismos e as tensões que envolveram a produção de conhecimento e a criação de regimes de verdade para a gestão de Angola. Pela mão desses alunos e da sua participação na malha administrativa construída no território angolano nos últimos anos do colonialismo português, legitimou-se a necessidade de um Estado para Angola e de um centro de referência acadêmica que o alimentou e que esteve longe de conhecer os verdadeiros problemas dos povos com os quais mantiveram contato.

\section{BIBLIOGRAFIA}

ABRANTES, Carla Susana Alem. 2012. "Problemas" e "soluções" para a gestão de Angola: um estudo a partir do ensino superior de administração colonial, 1950-1960. Tese de doutorado, Rio de Janeiro, Museu Nacional/Universidade Federal do Rio de Janeiro.

ALEXANDRE, Valentim. 2000. Velho Brasil, Novas Áfricas. Porto: Afrontamento.

ANDERSON, Perry. 1963. Le Portugal et la fin de l'ultra-colonialisme. Paris: François Maspero.

ASAD, Talal (ed.). 1973. Anthropology and the colonial encounter. New York: Humanities Press.

BASTOS, Cristiana. 1998. “Tristes trópicos e alegres luso-tropicalismos: das notas de viagem em Lévi-Strauss e Gilberto Freyre”. Análise Social, XXXIII (146-147):415-432.

2003. "Um luso-tropicalismo às avessas: colonialismo científico, aclimação e pureza racial em Germano Correia". In: M.C. Ribeiro \& A. P. Ferreira (orgs.). Fantasmas e fantasias imperiais no imaginário português contemporâneo. Porto: Campo das Letras. pp. 227-253.

BENDER, Gerald. 1980. Angola sob o domínio português - Mito e Realidade. Lisboa: Sá da Costa. 
BOURDIEU, Pierre. 1968. “Campo Intelectual e projeto criador”. In: Jean Pouillon et al. Problemas do Estruturalismo. Rio de Janeiro: Zahar. pp. 105-146.

CARVALHO, Clara. 2004. "O olhar colonial: antropologia e fotografia no Centro de Estudos da Guiné Portuguesa”. In: Clara Carvalho (org.). A Persistência da História- Passado e Contemporaneidade em África. Lisboa: Imprensa de Ciências Sociais (ICS).

CASTANHEIRA, Américo. 1950. "Trabalho indígena”. Algumas considerações acerca do problema da mão de obra indígena nas colónias de Timor e de Angola. Dissertação, Escola Superior Colonial.

CASTELO, Cláudia. 1998. "O modo português de estar no mundo". O luso-tropicalismo e a ideologia colonial portuguesa (1933-1961). Lisboa: Edições Afrontamento.

2012. "Investigação científica e política colonial portuguesa: evolução e articulações, 1936-1974”. História, Ciências, Saúde - Manguinhos, Rio de Janeiro, 19 (2):391-408.

CHILCOTE, Ronald H. 1967. Portuguese Africa. Englewood Cliffs, New Jersey: Prentice-Hall, Inc. COHN, Bernard S. 1996. Colonialism and its forms of knowledge. Princeton: Princeton University Press.

COMMAROFF, John. 1989. "Images of Empire, Contests of Conscience: Models of Colonial Domination in South Africa”. American Ethnologist, 16 (4):661-685.

CONCEIÇÃO NETO, Maria da. 1997. "Ideologias, Contradições e Mistificações da colonização de Angola no século XX”. Lusotopie, Bordeaux, pp. 327-359.

COOPER, Frederick. 2005. Colonialism in Question: Theory, Knowledge, History. London: University of California Press.

DIRKS, Nicholas B. (ed.). 1992. Colonialism and culture. Michigan: The University of Michigan Press. DUFFY, James. 1959. Portuguese Africa. Cambridge, Massachussetts: Harvard University Press; London: Oxford University Press.

FERREIRA, Eduardo de Sousa. 1977. o fim de uma era: o colonialismo português em África. Lisboa: Livraria Sá da Costa Editora.

FREYRE, Gilberto. 1951. O mundo que o português criou. Lisboa: Edições Livros do Brasil.

1952. Aventura e rotina: sugestões de uma viagem à procura das constantes portuguesas de caráter e ação. Lisboa: Livros do Brasil.

FOUCAULT, Michel. 1971. "Sobre a Arqueologia das Ciências. Resposta ao Círculo Epistemológico”. In: _-_ et alli. Estruturalismo e teoria da linguagem. Petrópolis: Vozes. pp. 9-55.

GALLO, Donato. 1988. Antropologia e Colonialismo: O Saber Português. Lisboa: Edição ER - O Heptágono.

JERÓNIMO, Miguel Bandeira. 2010. Livros brancos, almas negras: a "Missão Civilizadora" do colonialismo português (c. 1870-1930). Lisboa: Instituto de Ciências Sociais, Imprensa de Ciências Sociais.

LEAL, João. 2006. Antropologia em Portugal: Mestres, Percursos, Transições. Lisboa: Livros Horizonte.

MACAGNO, Lorenzo. 2001. “O discurso colonial e a fabricação dos usos e costumes: Antonio Ennes e a 'Geração de 95'”. In: Peter Fry (org.). Moçambique: Ensaios; Rio de Janeiro: Editora Universidade Federal do Rio de Janeiro.

MAINO, Elisabetta. 2005. "Pour une généalogie de l'africanisme portugais". Cahiers d'études africaines, n. 177. 
MANDANI, Mahmood. 1996. Citizen and Subject. Contemporary Africa and the Legacy of Late Colonialism. Princeton, New Jersey: Princeton University Press.

_-_-. 2012. Define and Rule - Native as Political Identity. London: Cambridge/ Harvard University Press.

MENDES, Afonso. 1958. A Huila e Moçâmendes. Considerações sobre o trabalho indígena. Lisboa: Ministério do Ultramar, Junta de Investigações do Ultramar.

MONTEIRO, José Alberto Pereira. 1959. o problema do trabalho dos indígenas (alguns aspectos). Dissertação, Instituto Superior de Estudos Ultramarinos (ISEU).

MOURA, João Herculano Rodrigues de. 1955. A Organização Internacional do Trabalho e os Territórios dependentes. Normas de Política Social. Dissertação, Instituto Superior de Estudos Ultramarinos (ISEU).

PAULO, João Carlos Duarte. 1992. A "Honra da Bandeira". A educação colonial no sistema de ensino português (1926-1946). Dissertação, Universidade Nova de Lisboa.

2001. “Cultura e ideologia colonial”. In: Serrão \& Marques (orgs). Nova História da Expansão Portuguesa: O Império Africano (1890-1930). Vol. VI. Lisboa: Editorial Estampa.

PÉLISSIER, René. 1979. Le Naufrage des Caravelles. Études sur la fin de l’Empire Portugais (1961-1975). Orgeval, França: Editions Pélissier.

PEREIRA, Rui. 1987. “O desenvolvimento da ciência antropológica na empresa colonial do Estado Novo”. In: António Costa Pinto. O Estado Novo: das Origens ao Fim da Autarcia (1926-1959). Colóquios sobre o Estado Novo. Vol. III. Lisboa: Editorial Fragmentos Ltd.

PEREIRA NETO, João. 1960. o progresso econômico e social das populações indígenas - na África do Sul do Saara. Dissertação, Instituto Superior de Estudos Ultramarinos (ISEU).

RODRÍGUEZ-PIÑERO, Luis. 2005. Indigenous Peoples, Postcolonialism, and International Law - The ILO Regime (1919-1989). Oxford: Oxford University Press.

SILVA, Cristina Nogueira da. 2009. Constitucionalismo e Império. A cidadania no Ultramar Português. Lisboa: Edições Almedina S.A.

SILVA, Elisete Marques. 2003. Impactos da Ocupação Colonial nas Sociedades Rurais do Sul de Angola. Lisboa: ISCTE.

SOARES, Amadeu Castilho. 1961. Política de Bem-Estar Rural em Angola. Lisboa: Junta de Investigações do Ultramar, Centro de Estudos Políticos e Sociais (Estudos em Ciência Política e Social, n. 49).

2002. “O homem que 'revolucionou' o português”. Entrevista: Jornal O Independente, Lisboa.

. 2004. “Universidade em Angola: A sua criação em 1962”. Episteme. Revista Multidisciplinar da Universidade Técnica de Lisboa. Lisboa, Ano IV, 2 ${ }^{\underline{a}}$ série, n. 13-14.

SOUZA LIMA, Antonio Carlos de. 1995. Um grande cerco de paz: poder tutelar, indianidade e formação do Estado no Brasil. Petrópolis, RJ: Vozes.

2007. “Tradições de conhecimento na gestão colonial da desigualdade: reflexões a partir da administração indigenista no Brasil”. In: Cristiana Bastos et alli. Trânsitos Coloniais: diálogos críticos luso-brasileiros. Campinas, SP: Editora da Unicamp.

STOLER, Ann Laura. 2009. Along the archival grain: epistemic anxieties and colonial common sense. Princeton and Oxford: Princeton University Press. 
THOMAS, Nicholas. 1994. Colonialism's Culture: Anthropology, Travel and Government. Princeton, New Jersey: Princeton University Press.

THOMAZ, Omar. 2007. “Tigres de papel: Gilberto Freyre, Portugal e os países africanos de língua oficial portuguesa”. In: Cristiana Bastos et alli. Trânsitos Coloniais: diálogos críticos luso-brasileiros. Campinas, SP: Editora da Unicamp.

TILLY, Charles. 1997. Roads from past to future. Lanham: Rowman \& Littlefield Publishers, Inc. 2000. "How do relations store histories". Annual Review of Sociology, 26:721-723.

TRAJANO FILHO, Wilson. 2003. Pequenos mas honrados: um jeito português de ser na metrópole e nas colônias. Brasília: Série Antropologia.

WHEELER, Douglas \& PELISSIER, René. 2009. História de Angola. Lisboa: Edições Tinta-da-China.

\section{NOTAS}

1. Seguirei, neste artigo, o seguinte padrão de grafia: i) itálicos para categorias retiradas do contexto de pesquisa que estão sob análise e termos em línguas estrangeiras; e ii) aspas para outros termos e expressões da pesquisa, ironias e citações retiradas da bibliografia de referência, como é usual.

2. Tratarei aqui do colonialismo português em Angola. Para um território grande e com variada geografia, sua população, de 5 milhões em 1950, era esparsa e com uma densidade inferior à média do continente africano, possivelmente devido à sangria pelo comércio de escravos ao longo de um período de tempo relativamente longo. Sua sociedade era composta por vários grupos culturais, na sua maior parte falantes da língua bantu (dentre elas, umbundo, kimbundo, kikongo e chokwe-lunda), totalizando 90 a 100 grupos étnicos. Os principais se distribuíam da seguinte forma: os Bacongo ao norte; os Quimbundo ao sul; os Ovimbundo no planalto central de Angola, grupo cultural mais numeroso, com orientação para leste; os Lunda-Quioco a nordeste; os povos Nganguela a leste, entre Ovimbundo e Quioco-Lunda; o povo Nyaneka-Humbe localizava-se na região do planalto da Humpata, na Huíla e no Vale Cunene; os Herero a sudoeste; os povos Ambo, nas planícies a leste do Cunene; e os povos não Bantu, nos territórios áridos do sul de Angola. Em meio a essa diversidade populacional, os portugueses eram um povo minoritário que chegou ao território em 1482, pelas mãos do navegador português Diogo Cão, tendo estabelecido o primeiro contato com o maior reino bantu da África Central Ocidental, o Reino do Congo. Trata-se de uma presença de quatro séculos, com um movimento de expansão de fronteiras e deslocamentos que envolveram relações amistosas e de conflito, comércio de escravos, conquista e controle de terras e da população, e resistência, muita resistência. Para mais sobre a história do colonialismo em Angola, ver Wheeler e Pélissier (2009).

3. As dissertações de licenciatura eram trabalhos finais de alunos do ensino superior especializado, produzidas para a obtenção de um diploma que habilitaria esses alunos para posições superiores nos quadros da administração colonial. Tais textos informavam imagens sobre Angola construídas a partir das temáticas de ensino e de experiências diversas de pesquisa. Um dos principais objetivos das dissertações era a formulação de um "problema" e a identificação de ações destinadas à sua "solução". As dissertações eram textos menores (no âmbito da ciência colonial como um todo), não publicados e guardados nos arquivos da biblioteca da instituição de ensino. Das seis dissertações aqui analisadas (Castanheira, 1950; Moura, 1955; Mendes, 1958; Monteiro, 1959; Pereira Neto, 1960; Soares, 1961), apenas duas foram publicadas (Mendes, 1958; Soares, 1961) em um contexto histórico específico que tornava necessária a exibição, a 
concomitante valorização de temas e do centro de pesquisa e ensino, portanto, da ciência colonial portuguesa.

4. Essa instituição de ensino foi criada em 1906 como Escola Colonial, a partir dos desígnios da Sociedade de Geografia de Lisboa (SGL). Ao longo das primeiras décadas de existência, a Escola Colonial coexistiu com a ocupação militar, chegando a 1926 com diferentes propostas de gestão civil dos territórios. Neste mesmo ano passou a ser designada de Escola Superior Colonial (ESC), considerada a "escola das escolas" em função da sua participação ativa na divulgação da ideia de Portugal como um país colonial. Em 1954, foi renomeada Instituto Superior de Estudos Ultramarinos (ISEU) por sua especialização em "problemas" do ultramar diante das necessárias reformas de um país que deixou de ser, formalmente, uma metrópole colonial para se transformar em um Estado nacional com territórios estrangeiros dependentes - as "províncias ultramarinas". Em 1961 tornou-se o Instituto Superior de Ciências Sociais e Política Ultramarina (ISCSPU). A sua existência faz parte de um quadro mais amplo de atividades de outras instituições de ensino nas metrópoles coloniais, como na França, na Inglaterra e na Bélgica, e que informaram às novas gerações padrões de como lidar com as populações autóctones dos territórios conquistados. Para mais sobre a Escola Colonial, ver Paulo (1992, 2001).

5. O controle da mão de obra foi sempre um dos grandes "problemas" da colonização, daí a importância dos documentos legislativos referentes ao trabalho africano publicados desde 1899, quando as novas propostas imperialistas ganharam força nos anos que se seguiram à abolição da escravatura. O Estatuto do Indigenato foi criado em 1926 e mantido em vigor, salvo pequenas reformulações, durante 35 anos até ser abolido em 1961. Nele, o africano era definido pela obrigação para o trabalho e como o principal objeto da ação colonizadora (Duffy, 1959). Por meio dele, também se distinguiam os civis dos não civis - os primeiros, portugueses natos e indígenas assimilados; os segundos, indígenas submetidos a esta lei especial que determinou, para além da obrigação do trabalho, a proteção de suas tradições indígenas e a garantia dos direitos naturais e incondicionais sob a forma de tutela.

6. A questão da migração da população do campo para as grandes cidades também é objeto de nota no olhar de Soares, que a considera como uma "massa de nativos", "uma corrente humana rústico-urbana", "libertos da disciplina tribal" que o "progresso civilizador da colonização desencadeou" (Soares, 1961:174). No entanto, o tema do urbano tem uma ênfase menor na dissertação, que trata prioritariamente do mundo rural.

7. A JIU foi uma das promotoras da missão em 1957 para Angola, tendo se denominado "Missão para o estudo da atração das grandes cidades e do bem-estar rural no ultramar português", em colaboração com o Centro de Estudos Políticos e Sociais (CEPS). Este centro foi criado em 1956 por Adriano Moreira para “[...] coordenar, estimular e promover o estudo dos fenômenos políticos e sociais verificados em comunidades formadas em territórios ultramarinos ou relacionados com estas, observando e expondo especialmente os fundamentos, as características e os resultados da ação desenvolvida pelos portugueses no ultramar" (Portaria no 15.737 de 15 de fevereiro de 1956). 8. As referências à sociologia mexicana em Castilho Soares (1961) foram retiradas de textos publicados pela Comissão de Cooperação Técnica na África ao Sul do Saara (CCTA), pelos Estudios Sociológicos (México) e ainda pelo 6º Congresso de Sociologia realizado no México, em 1955.

9. Foi somente em 1956 que a Convenção do Trabalho Obrigatório de 1930 foi assinada por Portugal, sinalizado a abertura do país para as discussões internacionais. No início dos anos 1950, o governo português enviou representantes para a elaboração de uma nova convenção no âmbito da OIT: a Convenção de 1957, que estabelecia regras para a integração das populações indígenas aos países independentes (Rodríguez-Piñero, 2005:8-9). Tratava-se de uma convenção a ser validada por "países independentes", muito embora tenha sido ratificada por Portugal, um país colonial em 1960, sob a alegação de que possuía populações indígenas participantes de sua nação pluricontinental - argumento que também serviu para legitimar a continuidade do colonialismo diante da comunidade internacional (Rodríguez-Piñero, 2005:239-240). 
10. Cristina Nogueira Silva (2009:21-22) faz referência às teorias da administração colonial de finais do século XIX e primeiros anos do século XX. O debate foi impulsionado e promovido por diferentes participantes da sociedade metropolitana portuguesa: sócios e colaboradores da Sociedade de Geografia de Lisboa, professores da Universidade de Coimbra, em especial os regentes da cadeira de Direito Colonial, administradores coloniais, oficiais do exército, comissários régios e ministros.

11. O Plano de Fomento para as colônias a que se refere Castilho Soares foi lançado em 1959 e tinha como objetivo a intensificação do povoamento branco e a ampliação de infraestruturas, com pouca ênfase em investimentos sociais e fomento de estruturas nativas, como sugere Castelo (2012:397). Ao contrário do que a narrativa de Castilho Soares sugere, a modernização das colônias passaria pela presença de um maior número de europeus no território colonial, estes considerados os principais agentes do modelo de desenvolvimento proposto para Angola.

12. O estudo desenvolvido por Castilho Soares foi publicado pelo Centro de Estudos Políticos e Sociais (CEPS) dois anos depois de escrito, em 1961, e seu autor, já licenciado, convidado pelo então ministro do Ultramar, Adriano Moreira, a assumir as funções de secretário provincial de Educação - uma das altas posições do governo em Angola. A política social que desenvolveu para o Plano de Governo de Angola em 1962 partiu da sua dissertação de licenciatura, que estabelecia "os objetivos e estratégias do desenvolvimento econômico e social de Angola" (Soares, 2004:57). Sob a coordenação de Castilho Soares, os planos de "massificação do português às zonas rurais de Angola" e as propostas de "levar a educação à sanzala" foram criados. Mais recentemente, no contexto pós-colonial, Castilho Soares foi considerado o principal teórico da educação para Angola, o homem que "revolucionou o português", conforme expresso no jornal 0 Independente, em 2002.

13. Tal órgão substituiu a antiga Repartição dos Negócios Indígenas, extinta nesse mesmo ano, 1962. Esta foi uma repartição com origens na Secretaria dos Negócios Indígenas de 1913, criada para tratar dos assuntos indígenas (trabalho, justiça, serviço militar, impostos e outros) na sequência da legislação laboral de 1899 e ligada às propostas elaboradas por Antonio Ennes, consideradas a base da moderna política colonial portuguesa (Duffy, 1959). As reformas trabalhistas de Ennes emergiram na nova configuração política após a abolição da escravatura e no auge das economias de plantação, nas quais se defendiam, ao mesmo tempo, os mercados e os usos e costumes dos indígenas (Macagno, 2001:69).

\section{RESUMOS}

O conhecimento científico produzido no colonialismo português contribuiu para reforçar a ideia de superioridade racial e missão histórica do povo português para a ocupação de territórios ultramarinos, em especial no continente africano. Com o objetivo de explicitar as agências e a complexidade da dominação colonial, este artigo se propõe a analisar a expansão portuguesa em Angola a partir de um contexto particular dos anos 1950: o ensino superior colonial em Lisboa. Os repertórios dos alunos de uma instituição de ensino voltada para a formação de quadros para as colônias revelam o modo como o saber contribuiu para ampliar as redes de administração e promover o Estado colonial em Angola. Em meio à disputa sobre os modos de representar as populações angolanas - trabalhadores indígenas e agricultores - emergem os projetos de educação para a colônia como solução para manter os africanos como mão de obra para a economia colonial. 
In the Portuguese colonialism, knowledge was produced to reinforce the racial superiority and the nation's historical mission to occupy foreign territories. This article explores the colonial experience in a particular context of the Portuguese expansion in Angola: the higher colonial education in Lisbon. The work of students of the Instituto Superior de Estudos Ultramarinos (ISEU) reveals some of the paths in which knowledge contributed to amplify the administration network and promote the colonial State in Angola. Through contentious repertories, the colonial population was represented - indigenous workers and peasants - and new educational projects emerged for Angola in the end of the 1950s as a solution to maintain the Africans as workforce to the colonial economy.

\section{ÍNDICE}

Keywords: Portuguese colonialism, colonial ideology, colonial higher education, compulsory labor, Angola

Palavras-chave: Colonialismo português, ideologia colonial, ensino superior colonial, trabalho compulsório, Angola

\section{AUTOR}

\section{CARLA SUSANA ALEM ABRANTES}

UNILAB. Carla Susana Alem Abrantes é professora de Antropologia da UNILAB, Universidade da Integração Internacional da Lusofonia Afro-Brasileira, em Redenção, Ceará, Brasil. Defendeu sua tese de doutorado em 2012 com o título "Problemas" e "soluções" para a gestão de Angola: um estudo a partir do ensino superior de administração colonial, 1950-1960, no Programa de Pós-Graduação em Antropologia Social do Museu Nacional, Universidade Federal do Rio de Janeiro (PPGAS/MN/ UFRJ). Suas áreas de interesse de pesquisa são Colonialismo Português, Administração Colonial e Pensamento Social. É líder do grupo Cultura, Desenvolvimento e Cooperação Internacional da UNILAB e pesquisadora do LACED/MN/UFRJ - Laboratório de Pesquisas em Etnicidade, Cultura e Desenvolvimento.contato: sabrantes@gmail.com 